\title{
COMPOSIÇÃO ESPECÍFICA DOS CRUSTÁCEOS DE ÁGUAS PROFUNDAS NA PLATAFORMA CONTINENTAL EXTERNA E TALUDE SUPERIOR DO ESTADO DE PERNAMBUCO
}

\author{
Ferreira, R.C.P. ${ }^{1}{ }^{*}$; Pires, A.M.A. ${ }^{1}$; Roque, P. ${ }^{1}$; Vedova, C.D. ${ }^{1}$; Viana, D.L. ${ }^{1}$ \& Hazin, F.H.V. ${ }^{1}$ \\ ${ }^{1}$ Universidade Federal Rural de Pernambuco (UFRPE), Campus Recife. Laboratório de Oceanografia Pesqueira.
}

*Autor correspondente: romulopires83@gmail.com

\begin{abstract}
O ambiente marinho sustenta várias populações de organismos, sendo os crustáceos um dos grupos mais comuns e diversos. Na plataforma continental externa e talude de Pernambuco, estudos sobre a fauna de crustáceos de águas profundas foram desenvolvidos pela primeira vez pelo Programa REVIZEE/NE, entre os anos de 1995 e 2000, entretanto continuam sendo até hoje praticamente as únicas existentes. No presente estudo, foram realizadas 45 prospecções exploratórias entre os meses de outubro de 2014 e setembro de 2017, utilizando-se armadilhas de fundo (covo), lançados no talude continental de Pernambuco em diferentes estratos de profundidade, objetivando aprofundar o conhecimento em relação a biodiversidade dos crustáceos de águas profundas. Os lançamentos foram distribuídos entre as coordenadas $07^{\circ} 50^{\prime} \mathrm{S}, 034^{\circ} 27^{\prime} \mathrm{O}$ e $08^{\circ} 52^{\prime} \mathrm{S}, 034^{\circ} 47^{\prime} \mathrm{O}$, em profundidades variando entre $218 \mathrm{~m}$ e $508 \mathrm{~m}$, com a maioria das estações tendo se situado em isóbata próxima a $300 \mathrm{~m}$. Os exemplares foram identificados ao menor nível taxonômico possível, com base na literatura existente. Quatrocentos e sessenta (460) indivíduos foram capturados, representados por 10 espécies, distribuídas em duas ordens: Decapoda e Isopoda. As espécies decápodas pertenciam a três infraordens: Brachyura (Rochinia crassa, Rochinia gracilipes, Stenocionops spinosissimus e Bathynectes longispina), Caridea (Plesionika edwardsii e Heterocarpus ensifer) e Anomura (Pagurus sp.); enquanto que os indivíduos da ordem Isopoda pertenciam a subordem Cymothoida (Bathynomus giganteus, B. miyarei e B. obtusus). As espécies de Caridea foram as que apresentaram maior abundância entre os crustáceos da megafauna bentônica coletados na plataforma continental externa de Pernambuco, reflexo das capturas elevadas do Plesionika edwardsii, com188. A segunda espécie mais abundante nas capturas foi o isópode Bathynomus miyarei, com 193 indivíduos tendo sido capturados. As espécies Bathynomus giganteus, B. miyarei. B. obtusus e Pagurus sp. foram capturadas pela primeira vez em águas pernambucanas, ampliando sua distribuição espacial. Tais registros, no entanto, focaram na composição e abundância, permanecendo praticamente desconhecidas informações sobre a sua biologia, tornando necessário futuros estudos que possam elucidar o modo de vida dessas espécies.
\end{abstract}

Palavras-chave: biodiversidade, crustáceos, águas profundas, Nordeste, Brasil. 